\title{
Common fixed points of ordered g-quasicontractions and weak contractions in ordered metric spaces
}

\author{
Zoran Golubović ${ }^{\text {, Zoran Kadelburg }}{ }^{2}$ and Stojan Radenović ${ }^{*}$
}

\footnotetext{
* Correspondence: radens@beotel. net

${ }^{1}$ Faculty of Mechanical Engineering, University of Belgrade, Kraljice Marije 16, Beograd 11120, Serbia Full list of author information is available at the end of the article
}

\begin{abstract}
We introduce ordered quasicontractions and g-quasicontractions in partially ordered metric spaces and prove the respective coincidence point and (common) fixed point results. An example shows that the new concepts are distinct from the existing ones. We also prove fixed point theorems for mappings satisfying so-called weak contractive conditions in the setting of partially ordered metric space. Hence, generalizations of several known results are obtained.

Mathematics Subject Classification (2010): 47H10; 47N10.
\end{abstract}

Keywords: partially ordered metric space, g-quasicontraction, weak contraction, coincidence point, common fixed point

\section{Introduction}

It is well known that the Banach contraction principle has been generalized in various directions. A lot of authors have used generalized contractive conditions of the type

$$
d(f x, f y) \leq \lambda M(x, y)
$$

where $(X, d)$ is a metric space, $f, g: X \rightarrow X, \lambda \in[0,1)$ and $M(x, y)$ is the maximum of one of the sets

$$
\begin{gathered}
\{d(g x, g y)\}, \quad\{d(g x, g y), d(g x, f x), d(g y, f y)\}, \\
\left\{d(g x, g y), d(g x, f x), d(g y, f y), \frac{1}{2}(d(f x, g y)+d(g x, f y))\right\},
\end{gathered}
$$

and alike. To obtain results about coincidence points or common fixed points of mappings $f$ and $g$, in the case when $f X \subset g X$, usually the technique of so-called Jungck sequence $y_{n}=f x_{n}=g x_{n+1}$ was used (see, $[1,2]$ ).

In the case when

$$
M(x, y)=\max \{d(g x, g y), d(g x, f x), d(g y, f y), d(g x, f y), d(g y, f x)\},
$$

the mapping $f$ is called a $g$-quasicontraction (or simply quasicontraction if $g=i_{X}$ ), see $[3,4]$. In this case different techniques were used to obtain common fixed point results in the cited and subsequent articles.

\section{空


The existence of fixed points in partially ordered metric spaces was first investigated by Ran and Reurings [5], and then by Nieto and Lopez [6,7]. Further results in this direction were proved, e.g., in [8-16].

In Section 2 of this article, we introduce ordered quasicontractions and $g$-quasicontractions in partially ordered metric spaces and prove the respective (common) fixed point results. An example shows that the new concepts are distinct from the existing ones, so our results are extensions of known ones.

Recently, several authors (see, e.g., [13,17-23]) have begun to use more general conditions (so-called weak contractive conditions) of the type

$$
\psi(d(f x, f y)) \leq \psi(M(x, y))-\varphi(M(x, y)),
$$

where $\psi$ and $\phi$ are so-called control functions (see definition in Section 3). The usage of Jungck sequence is here also possible, but becomes more involved. Also, some applications were obtained, in particular when dealing with differential, matrix and integral equations (see, e.g., [5-7,10]).

In Section 3 of the present article, we consider weak contractive conditions in the setting of partially ordered metric space (it is then restricted to the case when $g x$ and $g y$ are comparable) and prove respective common fixed point theorems. These results can be considered as generalizations of theorems from [9-11] since control functions are more general than comparison functions used in these articles.

\section{Common fixed points of ordered $\boldsymbol{g}$-quasicontractions}

Consider a partially ordered set $(X, \preccurlyeq)$ and two self-maps $f, g: X \rightarrow X$ such that $f X \subset g X$. Following [9] we shall say that the mapping $f$ is $g$-nondecreasing (resp., $g$-nonincreasing) if $g x \leqslant g y \Rightarrow f x \leqslant f y$ (resp., $g x \leqslant g y \Rightarrow f x \geqslant f y$ ) holds for each $x, y \in X$.

For arbitrary $x_{0} \in X$ one can construct a so-called Jungck sequence $\left\{y_{n}\right\}$ in the following way: denote $y_{0}=f x_{0} \in f X \subset g X$; there exists $x_{1} \in X$ such that $g x_{1}=y_{0}=f x_{0}$; now $y_{1}=f x_{1} \in f X \subset g X$ and there exists $x_{2} \in X$ such that $g x_{2}=y_{1}=f x_{1}$ and the procedure can be continued. The following properties of this sequence can be easily deduced.

Lemma $11^{\circ}$ If $f$ is $g$-nondecreasing and $g x_{0} \leqslant f x_{0}$ (resp., $g x_{0} \geqslant f x_{0}$ ), then the sequence $\left\{y_{n}\right\}$ is nondecreasing (resp., nonincreasing) w.r.t. $\preccurlyeq$.

$2^{\circ}$ If $f$ is $g$-nonincreasing and $f_{0}$ is comparable with $g x_{0}$, then the sequence $\left\{y_{n}\right\}$ is not monotonous, but arbitrary two of its adjacent terms are comparable.

Proof $1^{\circ}$ It follows from $g x_{0} \leqslant f x_{0}=g x_{1}$ that $f x_{0} \leqslant f x_{1}$, i.e., $y_{0} \leqslant y_{1}$ and it is easy to proceed by induction. The other case follows similarly.

$2^{\circ}$ Let, e.g., $g x_{0} \leqslant f x_{0}=g x_{1}$. Then, by assumption, $f x_{0} \geqslant f x_{1}$, i.e., $y_{0} \geqslant y_{1}$. Now $g x_{1} \geqslant$ $g x_{2}$ implies $f x_{1} \leqslant f x_{2}$, i.e., $y_{1} \leqslant y_{2}$ and the conclusion again follows.

Putting $g=i_{X}$ (identity map) in the previous lemma, we obtain

Corollary $11^{\circ}$ If $f$ is nondecreasing and $x_{0} \leqslant f x_{0}$ (resp. $\left.x_{0} \geqslant f x_{0}\right)$, then the Picard sequence $\left\{f^{n} x_{0}\right\}$ is nondecreasing (nonincreasing) w.r.t. $\leqslant$.

$2^{\circ}$ If $f$ is nonincreasing and $f x_{0}$ is comparable with $x_{0}$, then the sequence $\left\{f^{p} x_{0}\right\}$ is not monotonous, but arbitrary two of its adjacent terms are comparable.

Quasicontractions and $g$-quasicontractions in metric spaces were first studied in $[3,4]$. We shall call the mapping $f$ an ordered g-quasicontraction if there exists $\lambda \in$ $(0,1)$ such that for each $x, y \in X$ satisfying $g y \leqslant g x$, the inequality 


$$
d(f x, f y) \leq \lambda \cdot M(x, y)
$$

holds, where

$$
M(x, y)=\max \{d(g x, g y), d(g x, f x), d(g y, f y), d(g x, f y), d(g y, f x)\} .
$$

Theorem 1 Let $(X, d, \preccurlyeq)$ be a partially ordered metric space and let $f, g: X \rightarrow X$ be two self-maps on $X$ satisfying the following conditions:

(i) $f X \subset g X$;

(ii) $g X$ is complete;

(iii) $f$ is $g$-nondecreasing;

(iv) $f$ is an ordered g-quasicontraction;

(v) there exists $x_{0} \in X$ such that $g x_{0} \leqslant f x_{0}$;

(vi) if $\left\{g x_{n}\right\}$ is a nondecreasing sequence that converges to some $g z \in g X$ then $g x_{n} \leqslant g z$ for each $n \in \mathbb{N}$ and $g z \leqslant g(g z)$.

Then $f$ and $g$ have a coincidence point, i.e., there exists $z \in X$ such that $f z=g z$. If, in addition, (vii) $f$ and $g$ are weakly compatible ([1,2]), i.e., $f x=g x$ implies $f g x=g f x$, for each $x \in X$, then they have a common fixed point.

Proof Starting with the point $x_{0}$ from condition $(v)$, construct a Jungck sequence $y_{n}=$ $f x_{n}=g x_{n+1}$. By Lemma 1, using condition (iii) we conclude that $\left\{y_{n}\right\}$ is nondecreasing. It can be proved by the Das-Naik's method (as in [8]) that $\left\{y_{n}\right\}$ is a Cauchy sequence. Since $g X$ is complete (condition (ii)), there exists $z \in X$ such that $y_{n} \rightarrow w=g z \in g X$. We shall prove that $f z=w$.

By condition $(v i), g x_{n} \leqslant g z$ holds. Hence, putting in the contractive condition (iv) $x=$ $x_{n}, y=z$, we obtain that

$$
d\left(f x_{n}, f z\right) \leq \lambda \max \left\{d\left(g x_{n}, g z\right), d\left(g x_{n}, f x_{n}\right), d(g z, f z), d\left(g x_{n}, f z\right), d\left(f x_{n}, g z\right)\right\},
$$

and passing to the limit when $n \rightarrow \infty$ (and using that $d\left(g x_{n}, f z\right) \leq d\left(g x_{n}, g z\right)+d(g z$, $f z)$ ) we deduce that

$$
d(f z, g z) \leq \lambda \max \{0,0, d(f z, g z), 0+d(g z, f z), 0\}=\lambda d(f z, g z) .
$$

It follows that $f z=g z=w$ and $f$ and $g$ have a coincidence point.

In the case when condition (vii) holds, we obtain that $f w=f g z=g f z=g w$ and it remains to prove that $f w=w$. By condition (vi) we have that $g z \leqslant g g z=g w$ and then $d$ $(f w, w)=d(f w, f z) \leq \lambda M(w, z)$, where

$$
\begin{aligned}
M(w, z) & =\max \{d(g w, g z), d(g w, f w), d(g z, f z), d(g w, f z), d(g z, f w)\} \\
& =\max \{d(f w, w), 0,0, d(f w, w), d(w, f w)\}=d(f w, w) .
\end{aligned}
$$

It follows that $f w=w$ and $w$ is a common fixed point for $f$ and $g$.

Remark 1 If condition $(v)$ in the previous theorem is replaced by $f x_{0} \leqslant g x_{0}$, the respective Jungck sequence is nonincreasing and the conclusion of the theorem holds.

Theorem 2 Let the conditions of Theorem 1 be satisfied, except that (iii), (v), and (vi) are, respectively, replaced by:

(iii') $f$ is g-nonincreasing;

(v') there exists $x_{0} \in X$ such that $f x_{0}$ and $g x_{0}$ are comparable; 
(vi') if $\left\{g x_{n}\right\}$ is a sequence in $g X$ which has comparable adjacent terms and that converges to some $g z \in g X$, then there exists a subsequence $\left\{g x_{n_{k}}\right\}$ of $\left\{g x_{n}\right\}$ having all the terms comparable with $g z$ and $g z$ is comparable with ggz.

Then all the conclusions of Theorem 1 hold.

Proof Regardless whether $f x_{0} \leqslant g x_{0}$ or $g x_{0} \leqslant f x_{0}$ (condition( $\left.v^{\prime}\right)$ ), Lemma 1 implies that the adjacent terms of the Jungck sequence $\left\{y_{n}\right\}$ are comparable. This is again sufficient to imply that $\left\{y_{n}\right\}$ is a Cauchy sequence. Hence, it converges to some $g z \in g X$.

By (vi'), there exists a subsequence $y_{n_{k}}=f x_{n_{k}}=g x_{n_{k}+1}, k \in \mathbb{N}$, having all the terms comparable with $g z$. Hence, we can apply the contractive condition to obtain $d\left(f z, f x_{n_{k}}\right) \leq \lambda M\left(z, x_{n_{k}}\right)$ where

$$
\begin{aligned}
M\left(z, x_{n_{k}}\right) & =\max \left\{d\left(g z, g x_{n_{k}}\right), d(g z, f z), d\left(g x_{n_{k}}, f x_{n_{k}}\right), d\left(g x_{n_{k}}, f z\right), d\left(g z, f x_{n_{k}}\right)\right\} \\
& \rightarrow \max \{0, d(f z, g z), 0, d(g z, f z), 0\}=d(f z, g z) \quad(k \rightarrow \infty),
\end{aligned}
$$

and since $d(f z, g z) \leq d\left(f z, f x_{n_{k}}\right)+d\left(f x_{n_{k}}, g z\right)$ and $f x_{n_{k}} \rightarrow g z, k \rightarrow \infty$, it follows that $f z=g z=w$. The rest of conclusions follow in the same way as in Theorem 1.

Remark 2 If the five-term set in condition (2.1) is replaced by any of the following sets

$$
\begin{gathered}
\{d(g x, g y)\}, \quad\{d(g x, g y), d(g x, f x), d(g y, f y)\}, \\
\left\{d(g x, g y), \frac{1}{2}(d(g x, f x)+d(g y, f y)), \frac{1}{2}(d(g x, f y)+d(g y, f x))\right\}, \\
\left\{d(g x, g y), d(g x, f x), d(g y, f y), \frac{1}{2}(d(g x, f y)+d(g y, f x))\right\},
\end{gathered}
$$

then conclusions of both Theorems 1 and 2 remain valid. Thus, "ordered" versions of several generalized contraction theorems proved recently are obtained. In particular, the case of the set $\{d(g x, g y)\}$ gives a generalization of the results of Ran and Reurings [5], and Nieto and Lopez [6,7]. Note also that in most of these cases the proof that the Jungck sequence is a Cauchy sequence is directly obtained from the famous Jungck relation

$$
d\left(y_{n+1}, y_{n}\right) \leq \lambda d\left(y_{n}, y_{n-1}\right) .
$$

Remark 3 Taking $g=i_{X}$ we obtain "ordered" variants of various fixed point theorems involving one function $f$. In particular, the following "ordered" version of the known result of Cirić on quasicontractions [3] is obtained.

Corollary 2 (a) Let $(X, d, \preccurlyeq)$ be a partially ordered complete metric space and let $f$ : $X \rightarrow X$ be a nondecreasing self-map such that for some $\lambda \in(0,1)$,

$$
d(f x, f y) \leq \lambda \max \{d(x, y), d(x, f x), d(y, f y), d(x, f y), d(y, f x)\}
$$

holds for all $x, y \in X$ such that $y \leqslant x$. Suppose also that either

(i) $f$ is continuous or

(ii) for each nondecreasing sequence $\left\{x_{n}\right\}$ converging to some $u \in X, x_{n} \leqslant u$ holds for each $n \in \mathbb{N}$.

If there exists $x_{0} \in X$ such that $x_{0} \leqslant f x_{0}$, then $f$ has at least one fixed point. 
(b) The same holds if $f$ is nonincreasing, there exists $x_{0}$ comparable with $f x_{0}$ and (ii) is replaced by

(ii') if a sequence $\left\{x_{n}\right\}$ converging to some $u \in X$ has every two adjacent terms comparable, then there exists a subsequence $\left\{x_{n_{k}}\right\}$ having each term comparable with $x$.

Proof As an illustration, we include a direct proof of case (b) when condition (ii ') is fulfilled.

Let $u$ be the limit of the Picard sequence $\left\{f^{n} x_{0}\right\}$ and let $\left\{f^{n_{k}} x_{0}\right\}$ be a subsequence having all the terms comparable with $u$. Then we can apply contractivity condition to obtain

$$
\begin{gathered}
d\left(f u, f^{n_{k}+1} x_{0}\right) \leq \lambda \max \left\{d\left(u, f^{n_{k}} x_{0}\right), d(u, f u), d\left(f^{n_{k}} x_{0}, f^{n_{k}+1} x_{0}\right),\right. \\
\left.d\left(u, f^{n_{k}+1} x_{0}\right), d\left(f u, f^{n_{k}} x_{0}\right)\right\} .
\end{gathered}
$$

Using that $d(f u, u) \leq d\left(f u, f^{n_{k}+1} x_{0}\right)+d\left(f^{n_{k}+1} x_{0}, u\right)$ and passing to the limit when $k \rightarrow$ $\infty$ we get

$$
d(f u, u) \leq \lambda \max \{0, d(u, f u), 0,0, d(u, f u)\}=\lambda d(u, f u),
$$

and it follows that $f u=u$.

Note also that instead of the completeness of $X$, its $f$-orbitally completeness is sufficient to obtain the conclusion of the corollary.

It is clear that the following diagram, where arrows stand for implications, is valid:

$$
\begin{array}{ccc}
\text { contraction } & \rightarrow & \text { quasicontraction } \\
\downarrow & & \downarrow \\
\text { ordered contraction } & \rightarrow & \text { ordered quasicontraction }
\end{array}
$$

Reverse implications do not hold. An example of a quasicontraction which is not a contraction was given in [3]. We shall present an example of an ordered quasicontraction which is not a quasicontraction.

Example 1 Let $X=[0,4]$, equipped with the usual metric and ordered by

$$
x \preceq y \Leftrightarrow(x=y) \quad \text { or } \quad(x, y \in[1,4] \text { and } x \leq y) .
$$

Consider the function $f: X \rightarrow X, f x=\left\{\begin{array}{ll}2 x, & 0 \leq x<1, \\ \frac{1}{3}(x+5) & 1 \leq x \leq 4 .\end{array}\right.$ Then

$$
\begin{aligned}
M(x, y) & =\max _{0 \leq x<1}\{d(x, y), d(x, f x), d(y, f y), d(x, f y), d(y, f y)\} \\
& =\max _{0 \leq x<1 .}\{|x-y|,|x|,|y|,|x-2 y|,|y-2 x|\},
\end{aligned}
$$

and we have to check the condition $d(f x, f y)=2|x-y| \leq \lambda M(x, y)$. Taking in each of the possible five inequalities that $(x \rightarrow 1$ - and $y=0)$ or $(x=0$ and $y \rightarrow 1-)$ we obtain that $\lambda$ cannot be in the interval $[0,1)$. Hence, $f$ is not a quasicontraction. But it is an ordered contraction, and so an ordered quasicontraction, since $d(f x, f y) \leq \lambda d(x, y)$ holds for $\lambda \in\left[\frac{1}{3}, 1\right)$ and all $x, y \in X$ such that $y \leqslant x$. 


\subsection{Uniqueness of the fixed point}

The following simple example shows that conditions of theorems in the previous section are not sufficient for the uniqueness of fixed points (resp., common fixed points).

Example 2 Let $X=\{(1,0),(0,1)\}$, let $(a, b) \leqslant(c, d)$ if and only if $a \leq c$ and $b \leq d$, and let $d_{1}$ be the Euclidean metric. The function $f((x, y))=(x, y)$ is continuous. The only comparable pairs of points in $X$ are $(x, x)$ for $x \in X$ and then (2.2) reduces to $d_{1}(f x, f x)$ $=0$, and is trivially fulfilled. However, $f$ has two fixed points $(1,0)$ and $(0,1)$.

We shall give a sufficient condition for the uniqueness of the fixed point in the case of an ordered quasicontraction.

Theorem 3 Let all the conditions of Corollary 2 be satisfied with $\lambda \in(0,1 / 2)$ in the contractivity condition (2.2) and let for all $x, y \in X$ there exists $z \in X$ comparable with both of them. Then:

1. $f$ has a unique fixed point $u$;

2. for arbitrary $x_{0}$ which can be a starting point of the Picard sequence $\left\{f^{n} x_{0}\right\}$ this sequence converges to $u$.

Proof Let $u$ and $v$ be two fixed points of $f$. If these two points are comparable, then

$$
\begin{aligned}
d(u, v) & =d(f u, f v) \\
& \leq \lambda \max \{d(u, v), d(u, f u), d(v, f v), d(u, f v), d(v, f u)\}=\lambda d(u, v),
\end{aligned}
$$

implying $u=v$.

Suppose that $u$ and $v$ are incomparable and that $w \in X$ is comparable with both of them. We shall prove that $d\left(u, f^{n} w\right) \rightarrow 0$ and $d\left(v, f^{n} w\right) \rightarrow 0$ when $n \rightarrow \infty$, which, taking into account that $d(u, v) \leq d\left(u, f^{\imath} w\right)+d\left(f^{n} w, v\right)$, will imply that $d(u, v)=0$ and $u=v$. Indeed,

$$
\begin{aligned}
d\left(u, f^{n} w\right)= & d\left(f f^{n-1} u, f f^{n-1} w\right) \\
\leq & \lambda \max \left\{d\left(f^{n-1} u, f^{n-1} w\right), d\left(f^{n-1} u, f^{n} u\right), d\left(f^{n-1} w, f^{n} w\right),\right. \\
& \left.d\left(f^{n-1} u, f^{n} w\right), d\left(f^{n-1} w, f^{n} u\right)\right\} \\
\leq & \lambda \max \left\{d\left(u, f^{n-1} w\right), 0, d\left(f^{n-1} w, u\right)+d\left(u, f^{n} w\right)\right. \\
& \left.d\left(u, f^{n} w\right), d\left(f^{n-1} w, u\right)\right\} \\
= & \lambda\left(d\left(u, f^{n-1} w\right)+d\left(u, f^{n} w\right)\right) .
\end{aligned}
$$

It follows that

$$
d\left(u, f^{n} w\right) \leq \frac{\lambda}{1-\lambda} d\left(u, f^{n-1} w\right)=\mu d\left(u, f^{n-1} w\right) .
$$

Since $0<\lambda<1 / 2$, it is $\mu<1$ and it follows that $d\left(u, f^{n} w\right) \leq \mu^{n} d(u, w) \rightarrow 0$, when $n \rightarrow$ $\infty$. Similarly, $d\left(v, f^{n} w\right) \rightarrow 0$ and the proof is complete in the case, when $f$ is nondecreasing. The proof is similar when $f$ is nonincreasing.

It is an open question whether the previous theorem is true for $\lambda \in[1 / 2,1)$. Also, an open problem is to find sufficient conditions for the uniqueness of the common fixed point in the case of an ordered $g$-quasicontraction.

\section{Weak ordered contractions}

Functions $\psi, \phi:[0, \infty) \rightarrow[0, \infty)$ will be called control functions if:

(i) $\psi$ is a continuous nondecreasing function with $\psi(t)=0$ if and only if $t=0$, 
(ii) $\phi$ is a lower semi-continuous function with $\phi(t)=0$ if and only if $t=0$.

Let $(X, d)$ be a metric space and let $f, g: X \rightarrow X$. In the articles [20,21] (in the setting of metric spaces) and [12,13] (in the setting of ordered metric spaces) contractive conditions of the form

$$
\psi(d(f x, g y)) \leq \psi(M(x, y))-\varphi(M(x, y)),
$$

where

$$
M(x, y)=\max \left\{d(x, y), d(x, f x), d(y, g y), \frac{1}{2}(d(x, g y)+d(y, f x))\right\},
$$

were used to obtain common fixed points results. We shall use here the following condition

$$
\psi(d(f x, f y)) \leq \psi(M(x, y))-\varphi(M(x, y))
$$

where

$$
M(x, y)=\max \left\{d(g x, g y), d(g x, f x), d(g y, f y), \frac{1}{2}(d(g x, f y)+d(g y, f x))\right\} .
$$

Note that the respective result in the setting of ordered cone metric spaces is proved in [14].

Assertions similar to the following lemma (see, e.g., [24]) were used (and proved) in the course of proofs of several fixed point results in various articles.

Lemma 2 [24] Let $(X, d)$ be a metric space and let $\left\{y_{n}\right\}$ be a sequence in $X$ such that the sequence $\left\{d\left(y_{n+1}, y_{n}\right)\right\}$ is nonincreasing and

$$
\lim _{n \rightarrow \infty} d\left(y_{n+1}, y_{n}\right)=0 .
$$

If $\left\{y_{2 n}\right\}$ is not a Cauchy sequence, then there exist $\varepsilon>0$ and two sequences $\left\{m_{k}\right\}$ and $\left\{n_{k}\right\}$ of positive integers such that the following four sequences tend to $\varepsilon$, when $k \rightarrow \infty$ :

$$
d\left(y_{2 m_{k}}, y_{2 n_{k}}\right), d\left(y_{2 m_{k}}, y_{2 n_{k}+1}\right), d\left(y_{2 m_{k}-1}, y_{2 n_{k}}\right), d\left(y_{2 m_{k}-1}, y_{2 n_{k}+1}\right) .
$$

Theorem 4 Let $(X, d, \preccurlyeq)$ be a partially ordered metric space and let $f$, $g$ be two selfmaps on $X$ satisfying the following conditions:

(i) $f X \subset g X$;

(ii) $g X$ is complete;

(iii) $f$ is $g$-nondecreasing;

(iv) $f$ and $g$ satisfy condition (3.1) for each $x, y \in X$ such that $g y \leqslant g x$, where $(\psi, \phi)$ is a pair of control functions and $M(x, y)$ is defined by (3.2);

(v) there exists $x_{0} \in X$ such that $g x_{0} \leqslant f x_{0}$;

(vi) if $\left\{g x_{n}\right\}$ is a nondecreasing sequence that converges to some $g z \in g X$ then $g x_{n} \leqslant g z$ for each $n \in \mathbb{N}$ and $g z \preccurlyeq g(g z)$.

Then $f$ and $g$ have a coincidence point. If in addition,

(vii) $f$ and $g$ are weakly compatible,

then they have a common fixed point.

Proof As in the proof of Theorem 1, a nondecreasing Jungck sequence $y_{n}$ with $y_{n}=$ $f x_{n}=g x_{n+1}$ can be constructed. Consider the following two possibilities: $1^{\circ} y_{n_{0}}=y_{n_{0}+1}$ for some $n_{0} \in \mathbb{N}$ and $2^{\circ} y_{n} \neq y_{n+1}$ for each $n \in \mathbb{N}$. 
$1^{\circ}$ We shall prove that in this case $y_{n}=y_{n_{0}}$ for each $n \geq n_{0}$. Using that $g x_{n_{0}+1} \leq g x_{n_{0}+2}$ we obtain

$$
\begin{aligned}
\psi\left(d\left(y_{n_{0}+1}, y_{n_{0}+2}\right)\right) & =\psi\left(d\left(f x_{n_{0}+1}, f x_{n_{0}+2}\right)\right) \\
& \leq \psi\left(M\left(x_{n_{0}+1}, x_{n_{0}+2}\right)\right)-\varphi\left(M\left(x_{n_{0}+1}, x_{n_{0}+2}\right)\right)
\end{aligned}
$$

where

$$
\begin{aligned}
M\left(x_{n_{0}+1}, x_{n_{0}+2}\right)= & \max \left\{d\left(g x_{n_{0}+1}, g x_{n_{0}+2}\right), d\left(g x_{n_{0}+1}, f x_{n_{0}+1}\right), d\left(g x_{n_{0}+2}, f x_{n_{0}+2}\right),\right. \\
& \left.\frac{1}{2}\left(d\left(g x_{n_{0}+1}, f x_{n_{0}+2}\right)+d\left(g x_{n_{0}+2}, f x_{n_{0}+1}\right)\right)\right\} \\
= & \max \left\{d\left(y_{n_{0}}, y_{n_{0}+1}\right), d\left(y_{n_{0}}, y_{n_{0}+1}\right), d\left(y_{n_{0}+1}, y_{n_{0}+2}\right),\right. \\
& \left.\frac{1}{2}\left(d\left(y_{n_{0}}, y_{n_{0}+2}\right)+0\right)\right\} \\
= & \max \left\{0,0, d\left(y_{n_{0}+1}, y_{n_{0}+2}\right), \frac{1}{2} d\left(y_{n_{0}+1}, y_{n_{0}+2}\right)\right\} \\
= & d\left(y_{n_{0}+1}, y_{n_{0}+2}\right) .
\end{aligned}
$$

Hence $\psi\left(d\left(y_{n_{0}+1}, y_{n_{0}+2}\right)\right) \leq \psi\left(d\left(y_{n_{0}+1}, y_{n_{0}+2}\right)\right)-\varphi\left(d\left(y_{n_{0}+1}, y_{n_{0}+2}\right)\right)$ which, by the properties of control functions, implies that $d\left(y_{n_{0}+1}, y_{n_{0}+2}\right)=0$ and $y_{n_{0}+1}=y_{n_{0}+2}$. By induction, $y_{n}=y_{n_{0}}$ for each $n \geq n_{0}$. It follows that $g x_{n_{0}+1}=f x_{n_{0}+1}$ and $x_{n_{0}+1}$ is a coincidence point of $f$ and $g$.

Suppose that condition (vii) holds. Then also

$$
f y_{n_{0}}=f g x_{n_{0}+1}=g f x_{n_{0}+1}=g y_{n_{0}},
$$

and if we prove that $f y_{n_{0}}=y_{n_{0}}, \gamma_{n_{0}}$ will be a common fixed point for $f$ and $g$. Using condition ( $v i$ ) with $z=y_{n_{0}}$ we obtain that $g x_{n_{0}+1} \preceq g y_{n_{0}}$ and we can apply condition (iv) to obtain

$$
\psi\left(d\left(f x_{n_{0}+1}, f y_{n_{0}}\right)\right) \leq \psi\left(M\left(x_{n_{0}+1}, y_{n_{0}}\right)\right)-\varphi\left(M\left(x_{n_{0}+1}, y_{n_{0}}\right)\right),
$$

where

$$
\begin{aligned}
M\left(x_{n_{0}+1}, y_{n_{0}}\right)= & \max \left\{d\left(g x_{n_{0}+1}, g y_{n_{0}}\right), d\left(g x_{n_{0}+1}, f x_{n_{0}+1}\right), d\left(g y_{n_{0}}, f y_{n_{0}}\right),\right. \\
& \left.\frac{1}{2}\left(d\left(g n_{n_{0}+1}, f y_{n_{0}}\right)+d\left(g y_{n_{0}}, f x_{n_{0}+1}\right)\right)\right\} \\
= & \max \left\{d\left(y_{n_{0}}, f y_{n_{0}}\right), d\left(y_{n_{0}}, y_{n_{0}}\right), d\left(f y_{n_{0}}, f y_{n_{0}}\right),\right. \\
\left.\frac{1}{2}\left(d\left(y_{n_{0}}, f y_{n_{0}}\right)+d\left(f y_{n_{0}}, y_{n_{0}}\right)\right)\right\} & \\
= & d\left(y_{n_{0}}, f y_{n_{0}}\right) .
\end{aligned}
$$

Thus, $\psi\left(d\left(y_{n_{0}}, f y_{n_{0}}\right)\right) \leq \psi\left(d\left(y_{n_{0}}, f y_{n_{0}}\right)\right)-\varphi\left(d\left(y_{n_{0}}, f y_{n_{0}}\right)\right)$ and again using properties of control functions it follows that $f y_{n_{0}}=y_{n_{0}}$. This completes the proof of the theorem in the first case.

$2^{\circ}$ We shall prove that in this case $\left\{y_{n}\right\}$ is a Cauchy sequence. Since $g x_{n+1} \preccurlyeq g x_{n+2}$, we have that

$$
\begin{aligned}
\psi\left(d\left(y_{n+1}, y_{n+2}\right)\right) & =\psi\left(d\left(f x_{n+1}, f x_{n+2}\right)\right) \\
& \leq \psi\left(M\left(x_{n+1}, x_{n+2}\right)\right)-\varphi\left(M\left(x_{n+1}, x_{n+2}\right)\right)
\end{aligned}
$$


where

$$
\begin{aligned}
M\left(x_{n+1}, x_{n+2}\right)= & \max \left\{d\left(g x_{n+1}, g x_{n+2}\right), d\left(g x_{n+1}, f x_{n+1}\right), d\left(g x_{n+2}, f x_{n+2}\right),\right. \\
& \left.\frac{1}{2}\left(d\left(g x_{n+1}, f x_{n+2}\right)+d\left(g y_{n+2}, f x_{n+1}\right)\right)\right\} \\
= & \max \left\{d\left(y_{n}, y_{n+1}\right), d\left(y_{n}, y_{n+1}\right), d\left(y_{n+1}, y_{n+2}\right), \frac{1}{2} d\left(y_{n}, y_{n+2}\right)+0\right\} \\
= & \max \left\{d\left(y_{n}, y_{n+1}\right), d\left(y_{n+1}, y_{n+2}\right)\right\}
\end{aligned}
$$

$\left(d\left(y_{n}, y_{n+2}\right) \leq d\left(y_{n}, y_{n+1}\right)+d\left(y_{n+1}, y_{n+2}\right)\right.$ was used to obtain the last equality). If $d\left(y_{n+1}\right.$, $\left.y_{n+2}\right) \geq d\left(y_{n}, y_{n+1}\right)$, then it follows from

$$
\psi\left(d\left(y_{n+1}, y_{n+2}\right)\right) \leq \psi\left(d\left(y_{n+1}, y_{n+2}\right)\right)-\varphi\left(d\left(y_{n+1}, y_{n+2}\right)\right)
$$

and the properties of control functions that $d\left(y_{n+1}, y_{n+2}\right)=0$, contrary to the assumption that all terms of the sequence $\left\{y_{n}\right\}$ are distinct. Hence, $d\left(y_{n+1}, y_{n+2}\right)<d\left(y_{n}, y_{n+1}\right)$, i.e., the sequence $\left\{d\left(y_{n}, y_{n+1}\right)\right\}$ is decreasing. Therefore, it converges to some $d^{*} \leq 0$ when $n$ $\rightarrow \infty$. Then, $M\left(x_{n+1}, x_{n+2}\right) \rightarrow d^{*}, n \rightarrow \infty$.

From (3.4), passing to the (upper) limit when $n \rightarrow \infty$, it follows that

$$
\psi(d *) \leq \psi(d *)-\liminf _{n \rightarrow \infty} \varphi(d *) \leq \psi(d *)-\varphi(d *),
$$

i.e., $\phi\left(d^{*}\right)=0$ and $d^{*}=0$. We conclude that $d\left(y_{n}, y_{n+1}\right) \rightarrow 0, n \rightarrow \infty$. As a consequence, in order to prove that $\left\{y_{n}\right\}$ is a Cauchy sequence, it is enough to prove that $\left\{y_{2 n}\right\}$ is a Cauchy sequence.

Suppose that $\left\{y_{2 n}\right\}$ is not a Cauchy sequence. Then, by Lemma 2, there exist $\varepsilon>0$ and two sequences $\left\{m_{k}\right\}$ and $\left\{n_{k}\right\}$ of positive integers such that the sequences (3.3) tend to $\varepsilon$ when $k \rightarrow \infty$. Now, by definition of $M(x, y)$, we obtain that $M\left(x_{2 m_{k}}, x_{2 n_{k}+1}\right) \rightarrow \varepsilon, k \rightarrow \infty$. Indeed,

$$
\begin{aligned}
M( & \left.x_{2 m_{k}}, x_{2 n_{k}+1}\right) \\
= & \max \left\{d\left(g x_{2 m_{k}}, g x_{2 n_{k}+1}\right), d\left(g x_{2 m_{k}}, f x_{2 m_{k}}\right), d\left(g x_{2 n_{k}+1}, f x_{2 n_{k}+1}\right),\right. \\
& \left.\frac{1}{2}\left(d\left(f x_{2 m_{k}}, g x_{2 n_{k}+1}\right)+d\left(f x_{2 n_{k}+1}, g x_{2 m_{k}}\right)\right)\right\} \\
= & \max \left\{d\left(y_{2 m_{k}-1}, y_{2 n_{k}}\right), d\left(y_{2 m_{k}-1}, y_{2 m_{k}}\right), d\left(y_{2 n_{k}}, y_{2 n_{k}+1}\right),\right. \\
& \left.\frac{1}{2}\left(d\left(y_{2 m_{k}}, y_{2 n_{k}}\right)+d\left(y_{2 n_{k}+1}, y_{2 m_{k}-1}\right)\right)\right\} \\
\rightarrow & \max \left\{\varepsilon, 0,0, \frac{1}{2}(\varepsilon+\varepsilon)\right\}=\varepsilon .
\end{aligned}
$$

Now, putting $x=x_{2 m_{k}}$ and $y=x_{2 n_{k}+1}$ into the contractive condition (iv) (which is possible since $g x_{2 n_{k}+1}=y_{2 n_{k}}$ and $g x=g x_{2 m_{k}}=y_{2 m_{k}-1}$ are comparable), we get that

$$
\begin{aligned}
\psi\left(d\left(y_{2 m_{k}}, y_{2 n_{k}+1}\right)\right) & =\psi\left(d\left(f x_{2 m_{k}}, f x_{2 n_{k}+1}\right)\right) \\
& \leq \psi\left(M\left(x_{2 m_{k}}, x_{2 n_{k}+1}\right)\right)-\varphi\left(M\left(x_{2 m_{k}}, x_{2 n_{k}+1}\right)\right) .
\end{aligned}
$$

Passing to the limit when $k \rightarrow \infty$ and using properties of control functions, we obtain that $\psi(\varepsilon) \leq \psi(\varepsilon)-\phi(\varepsilon)$, which is in contradiction with $\varepsilon>0$.

The proof that $\left\{y_{n}\right\}$ is a Cauchy sequence is complete. By the assumption (ii), there exists $z \in X$ such that $g x_{n} \rightarrow g z$, when $n \rightarrow \infty$. We shall prove that $f z=g z$. 
Condition ( $v i)$ implies that $g x_{n} \preccurlyeq g z$ and we can apply contractive condition to obtain

$$
\psi\left(d\left(f x_{n}, f z\right)\right) \leq \psi\left(M\left(x_{n}, z\right)\right)-\varphi\left(M\left(x_{n}, z\right)\right),
$$

where

$$
\begin{aligned}
M\left(x_{n}, z\right) & =\max \left\{d\left(g x_{n}, g z\right), d\left(g x_{n}, f x_{n}\right), d(g z, f z), \frac{1}{2}\left(d\left(g x_{n}, f z\right)+d\left(g z, f x_{n}\right)\right)\right\} \\
& \rightarrow \max \left\{0,0, d(g z, f z), \frac{1}{2} d(g z, f z)\right\}=d(g z, f z) .
\end{aligned}
$$

Passing to the (upper) limit when $n \rightarrow \infty$ in (3.5) we obtain that

$$
\psi(d(g z, f z)) \leq \psi(d(g z, f z))-\varphi(d(g z, f z)),
$$

wherefrom $g z=f z$ follows. Hence, $z$ is a coincidence point of $f$ and $g$.

If condition (vii) is fulfilled, put $w=f z=g z$, and obtain that $f w=f g z=g f z=g w$. Using that $g z \leqslant g g z=g w$ it can be proved that $f w=g w=w$ in a similar way as it was done in the case $1^{\circ}$. The theorem is proved completely.

Remark 4 If the four-term set in condition (3.2) is replaced by any of the following sets

$$
\begin{gathered}
\{d(g x, g y)\}, \quad\{d(g x, g y), d(g x, f x), d(g y, f y)\}, \\
\left\{d(g x, g y), \frac{1}{2}(d(g x, f x), d(g y, f y)), \frac{1}{2}(d(g x, f y)+d(g y, f x))\right\},
\end{gathered}
$$

similar conclusions for the existence of common fixed points of mappings $f$ and $g$ can be obtained.

Remark 5 In his important article [22], Jachymski showed that some fixed point results based on weak contractive conditions involving functions $\psi$ and $\phi$ can be reduced to their counterparts using just one function, say $\phi^{\prime}$. We note that our results do not fall into this category, since conditions of our Theorem 4 are not covered by the conditions of [22, Theorem 7].

Remark 6 Very recently, Shatanawi et al. [25] have obtained some results closely related to the ones given in this section. However, their assumptions on the given mappings are different.

\section{Acknowledgements}

The authors thank the referees for their valuable comments that helped us to improve the text. The authors are thankful to the Ministry of Science and Technological Development of Serbia.

\section{Author details}

${ }^{1}$ Faculty of Mechanical Engineering, University of Belgrade, Kraljice Marije 16, Beograd 11120, Serbia ${ }^{2}$ Faculty of Mathematics, University of Belgrade, Studentski trg 16, Beograd 11000, Serbi

Authors' contributions

All authors contributed equally and significantly in writing this article. All authors read and approved the final manuscript.

\section{Competing interests}

The authors declare that they have no competing interests.

Received: 29 October 2011 Accepted: 21 February 2012 Published: 21 February 2012

References

1. Jungck, G: Commuting mappings and fixed points. Am Math Monthly. 83, 261-263 (1976). doi:10.2307/2318216 
2. Jungck, G: Compatible mappings and common fixed points. Int J Math Sci. 9, $771-779$ (1986). doi:10.1155/ S0161171286000935

3. Cirić, LjB: A generalization of Banach's contraction principle. Proc Am Math Soc. 45, 267-273 (1974)

4. Das, KM, Naik, KV: Common fixed point theorems for commuting maps on metric spaces. Proc Am Math Soc. 77, 369-373 (1979)

5. Ran, ACM, Reurings, MCB: A fixed point theorem in partially ordered sets and some application to matrix equations. Proc Am Math Soc. 132, 1435-1443 (2004). doi:10.1090/50002-9939-03-07220-4

6. Nieto, JJ, Lopez, RR: Contractive mapping theorems in partially ordered sets and applications to ordinary differential equations. Order. 22, 223-239 (2005). doi:10.1007/s11083-005-9018-5

7. Nieto, JJ, Lopez, RR: Existence and uniqueness of fixed point in partially ordered sets and applications to ordinary differential equations. Acta Math Sinica English Ser. 23(12):2205-2212 (2007). doi:10.1007/s10114-005-0769-0

8. O'Regan, D, Shahzad, N: Invariant approximations for generalized contractions. Numer Funct Anal Optim. 26(45):565-575 (2005). doi:10.1080/NFA-200067306

9. Cirić, Lj, Cakić, N, Rajović, M, Ume, JS: Monotone generalized nonlinear contractions in partially ordered metric spaces. Fixed Point Theory Appl. (2008)

10. O'Regan, D, Petrusel, A: Fixed point theorems for generalized contractions in ordered metric spaces. J Math Anal Appl. 341, 1241-1252 (2008). doi:10.1016/j.jmaa.2007.11.026

11. Agarwal, RP, El-Gebeily, MA, O'Regan, D: Generalized contractions in partially ordered metric spaces. Appl Anal. 87, 109-116 (2008). doi:10.1080/00036810701556151

12. Harjani, J, Sadarangani, K: Fixed point theorems for weakly contractive mappings in partially ordered sets. Nonlinear Anal. 71, 3402-3410 (2009)

13. Radenović, S, Kadelburg, Z: Generalized weak contractions in partially ordered metric spaces. Comput Math Appl. 60, 1776-1783 (2010). doi:10.1016/j.camwa.2010.07.008

14. Kadelburg, Z, Pavlović, M, Radenović, S: Common fixed point theorems for ordered contractions and quasicontractions in ordered cone metric spaces. Comput Math Appl. 59, 3148-3159 (2010). doi:10.1016/j.camwa.2010.02.039

15. Karapinar, E: Couple fixed point theorems for nonlinear contractions in cone metric spaces. Comput Math Appl. 59, 3656-3668 (2010). doi:10.1016/j.camwa.2010.03.062

16. Karapinar, E, Berinde, V: Quadruple fixed point theorems for nonlinear contractions in partially ordered metric spaces. Banach J Math Anal. 6, 74-89 (2012)

17. Alber, Yal, Guerre-Delabriere, S: Principle of weakly contractive maps in Hilbert spaces. In: Gohberg, I, Lyubich, Yu (eds.) New results in operator theory Advances and Applications, vol. 98, pp. 7-22. Birkhäuser Verlag, Basel (1997)

18. Rhoades, BE: Some theorems on weakly contractive maps. Nonlinear Anal. 47, 2683-2693 (2001). doi:10.1016/50362546X(01)00388-1

19. Berinde, V: Approximating fixed points of weak $\varphi$-contractions. Fixed Point Theory. 4, 131-142 (2003)

20. Zhang, Q, Song, Y: Fixed point theory for generalized $\varphi$-weak contractions. Appl Math Lett. 22, 75-78 (2009). doi:10.1016/.j.aml.2008.02.007

21. Dorić, D: Common fixed point for generalized $(\psi, \varphi)$-weak contractions. Appl Math Lett. 22, 1896-1900 (2009). doi:10.1016/j.aml.2009.08.001

22. Jachymski, J: Equivalent conditions for generalized contractions on (ordered) metric spaces. Nonlinear Anal TMA. 74 768-774 (2011). doi:10.1016/..na.2010.09.025

23. Aydi, $\mathrm{H}$, Karapinar, E, Shatanawi, W: Coupled fixed point results for $(\psi, \varphi)$-weakly contractive condition in ordered partial metric spaces. Comput Math Appl. 62, 4449-4460 (2011). doi:10.1016/j.camwa.2011.10.021

24. Radenović, S, Kadelburg, Z, Jandrlić, D, Jandrlić, A: Some results on weak contraction maps. Bull Iran Math Soc 192(1):111-31 (2011). available online since 30 March 2011

25. Shatanawi, W, Mustafa, Z, Tahat, N: Some coincidence point theorems for nonlinear contractions in ordered metric spaces. Fixed Point Theory Appl. 2011, 68 (2011). doi:10.1186/1687-1812-2011-68

doi:10.1186/1687-1812-2012-20

Cite this article as: Golubović et al:: Common fixed points of ordered g-quasicontractions and weak contractions in ordered metric spaces. Fixed Point Theory and Applications 2012 2012:20.

\section{Submit your manuscript to a SpringerOpen ${ }^{\circ}$ journal and benefit from:}

- Convenient online submission

- Rigorous peer review

- Immediate publication on acceptance

- Open access: articles freely available online

- High visibility within the field

- Retaining the copyright to your article

Submit your next manuscript at $\gg$ springeropen.com 